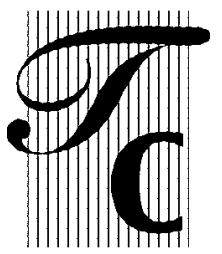

\title{
Emotions and criminal justice
}

\author{
SUSANNE KARSTEDT \\ Keele University, UK
}

\begin{abstract}
During the last decade, a process of 'emotionalization of law' has spread around the globe, changing the criminal justice system in many ways. Anger, disgust and shame are perceived as 'valuable barometers of social morality' and brought back to criminal procedures. The 'return of emotions' to penal law and criminal justice is linked to and illuminates the moral imagination of late modern societies. This article seeks to address two facets of the 'return of emotions' to criminal justice. The first part explores the changes in the public sphere and in the pattern of emotional culture in late modern societies that are responsible for the reemotionalization of the penal realm. In the second part, problems that emerge in the criminal justice system are addressed. Bringing emotions back involves profound problems that go beyond the mere instrumental use of emotions in criminal justice, or a restricted perspective of 'what works'. Three 'core' problems-and associated-questions are discussed: first, are emotional reactions towards crimes 'natural' or 'primordial' such that they should occupy a prominent place in criminal justice that has been unduly ignored? Second, and relatedly, do emotions constitute our moral principles? Finally, should institutions elicit or even require 'authentic emotions' from individuals? These questions are addressed within the framework of contemporary emotion theory and the consequences of this perspective for the 'use' of emotions in criminal justice are discussed.
\end{abstract}

\section{Key Words}

emotion $\bullet$ emotionalization $\bullet$ emotion theory $\bullet$ late modernity • penal law 


\section{Emotions and penal law}

Emotions pervade penal law and the criminal justice system. Offenders, victims and witnesses bring their emotions to the courtroom, criminal courts deal with crimes of passion, and their decisions can occasion public outrage and anger, or feelings of vengeance among victims. Offenders feel shame and remorse when they have transgressed the laws, and offences provoke feelings of moral disgust. At the same time, victims as well as offenders elicit our compassion and sympathy.

Law has by no means been blind to this invasion of emotions into its very realm. It explicitly references and grants legitimacy to emotions through legal defences (as in crimes of passion); by establishing specific categories of behaviour like 'hate crimes', or by restricting the admission of evidence that might influence the emotions of jury members and judges (as, for example, in victim statements-see Posner, 2000). Legal institutions and in particular the criminal justice system are the very institutions in society that are designed to deal with the most intense emotions and emotional conflicts, with individual as well as collective emotions. The criminal courts and procedures are a prominent institutional space and institutional mechanism for emotions in society. ${ }^{1}$

The particular position of penal law and the criminal justice system in the emotional space delineated by societies has long since captured the imagination of social theorists, and figures prominently in the work of Durkheim and Elias. Both realized that penal law was deeply embedded in the emotional culture of societies, and intricately linked to the structural and institutional patterns of society. Consequently, decisive changes in the 'morality' (Durkheim) and 'mentality' (Elias) of societies are at the roots of the historical development of penal law and punishment, and criminal justice illuminates-or more technically, indicates-subterranean shifts in the emotional culture of societies. Interestingly, both of these theorists interpreted the historical change from traditional to modern society as a pathway that continuously and consistently limited and changed the role of emotions in the public sphere, and, as a result, modes of penal law and punishment. Modern societies, highly differentiated and interdependent, rely on other and more subtle mechanisms to ensure compliance with norms than the crude and simple arousal of moral and collective emotions by criminal proceedings and the (public) execution of sanctions.

In jurisprudence, the history of penal law and criminal justice is in fact cast as a process that has more strictly confined and more precisely outlined the space of emotions, and limited the amount of emotionality that is admitted in courts. The conventional story of modern penal law portrays a narrowly delineated list and proper roles for emotions in the legal realm, so that emotions do not intrude into the true preserve of law: reason (Bandes, 1999a: 2). Such a juxtaposition of reason and emotion, one deeply embedded in modern thought, seems within the normative framework of 
jurisprudence to ignore vital facets of the actual role of emotions in law and legal procedures (see Douglas, 1993). The edifice of penal law itself is erected on a strong undercurrent of emotions: the fear of sanctions, that should instil compliance, or vengeance that is to be channelled by legal procedures (Elster, 1999). Popular wisdom as well as criminological theory have both established fear of sanctions as a cornerstone and powerful mechanism of the criminal justice system, the thing that makes it work.

Far from precluding rational action, emotions may facilitate a 'rational response'-for example, to the experience of injustice. The 'handling of emotions' within the criminal justice system is not a priori 'rational', neither in its procedural arrangements nor with regard to its final outcomes, but designed according to specific functions. Both offenders and victims react by no means in principle emotionally, but make 'rational decisions' when dealing with the criminal justice system: offenders try to find ways of beating the system, or victims weigh the advantages and disadvantages of invoking the law (Poletta, 2001). ${ }^{2}$

During the last decade, the secular process of restricting the space of emotions in the penal realm seems to have taken a turn towards bringing emotions back in. A process of 're-emotionalization of law' or the 'reassertion of emotionality in law' (Laster and O'Malley, 1996) spread around the globe, and has changed the criminal justice system in many ways. The 'return of emotions' to criminal justice and penal policies has occurred in two arenas: the emotionalization of public discourse about crime and criminal justice, and the implementation of sanctions in the criminal justice system that are explicitly based on-or designed to arouse-emotions. Both developments corresponded to the changing space of emotions and the emotional culture of late modern societies, and it can be assumed that these processes have fuelled one another.

This article seeks to address both these facets of the 'return of emotions' to criminal justice. In the first part, I argue that changes in the public sphere and emotional culture of late modern societies are responsible for the reemotionalization of the penal realm. In the second part, I address the problems that consequently emerge in the criminal justice system. Bringing emotions back involves profound problems that go beyond the mere instrumental use of emotions in criminal justice, or a restricted perspective of 'what works'. I will discuss three 'core' problems and a series of associated questions: first, are emotional reactions towards crimes 'natural' or 'primordial', such that they need not only a proper but a prominent place in criminal justice which has been unduly ignored? Second, and relatedly, do emotions constitute our moral principles? Finally, I deal with a series of questions concerning the invisibility of emotions; should institutions elicit or even require 'authentic emotions' from individuals? What is the different role and impact of emotions in criminal justice in a culture which ritualizes emotional expression or promotes individualistic, 
authentic expression? These questions will be addressed within the framework of contemporary emotion theory.

\section{The 'return of emotions'}

'The Return of Shame'-as described in a Newsweek article in 1995-has brought back an emotion to the criminal justice system that had been dismissed as hopelessly old-fashioned during previous decades. Judges in the United States were the first to remake the courts and the criminal justice system as a public space of emotions. Offenders were ordered by courts to wear T-shirts in public that identified them as thieves. Young offenders had to apologize on their knees to their victims with members of the community present. Sexual offenders had to erect signs on their front lawn warning the public about the inhabitant; another court order sent the victims of a burglary to the house of the offender to take from it what they liked (see Massaro, 1991, 1997; Anderson, 1995; Karstedt, 1996). What is striking about these sentences, is not only the explicit use of emotion, but the way it is done, the great emphasis placed on their publicness. The thin line between shame, humiliation and stigmatization was consistently ignored, and the question of whether shame has the impact intended if imposed in such ways never asked (see Elster, 1999: 145). The effects of constant and public terrorization of norm-violators by an emotional mechanism (which the judges assumed to be shame) on the offender and/or watching spectators was never questioned in these cases. The revival of shame in the first instance came with 'episodic, almost whimsical bursts of judicial, legislative or prosecutorial inspiration' (Massaro, 1991: 1940), which were nonetheless the first and most visible signs of the return of emotions.

The influential movement of restorative justice in criminology and criminal justice is based in contrast on a theoretical concept. In his book Crime, Shame and Reintegration (1989), Braithwaite carefully developed a theoretical argument to the effect that shaming the offence, but not the offender, will reintegrate the offender into the community. In indigenous procedures of 'conferencing' from New Zealand and Australia he found settings in which shaming and reintegration could simultaneously work. ${ }^{3}$ In particular, he gave the victims a strong role and presence in these procedures. Their participation should make the process of shaming powerful and lasting. The conferences were designed to allow for emotional experiences and expressions of shame, remorse, guilt and anger, but also of sympathy and forgiveness. The fact that procedures of restorative justice have become the most successful reform movement in criminal justice world-wide shows that the return of emotions has struck a cord in the criminal justice system and with the public. In instances as diverse as drunk driving, teenage shoplifting and domestic violence (as well as in the Truth and Reconciliation Commissions for perpetrators of past regimes) emotions were brought back into legal procedures and made an 
essential part of them. While restorative justice brought victims to centrestage, it made it perfectly clear that justice is relational, something that establishes an emotional connection between the victim, the offender and the often neglected actors who actually impose the punishment (see Elster, 1989; Karstedt, 1993).

Criminology and jurisprudence have rediscovered both individual and collective emotions (Skillen, 1980; Pratt, 2000; Freiberg, 2001). Leading figures in the economic analysis of law (Posner, 2000) have turned to emotions, and discovered that 'the violation of norms triggers strong, emotional reactions, in the offender as well as in others' (Elster, 1989: 100). But it comes as a striking fact that the 'moral sentiments' identified by most of these authors as the foundations of law are what can be termed 'negative emotions' (Solomon, 1990; Bandes, 1999b; Kahan, 1999; Posner, 2000). Moral disgust, revulsion and feelings of vengeance are found to be 'valuable barometers of societal morality' (Bandes, 1999a: 4), serving as a legitimate foundation for law and legal procedures. This stands in stark contrast to early theories on moral sentiments found in the writings of Adam Smith, Hume and Hutcheson. These authors embedded the moral bond in emotions of sympathy and empathy, wherein the 'strong sentiments of morals' are based on 'indignation' as well as 'tender-heartedness' (see, for a discussion, Solomon, 1990, 1994; Boltanski, 1999).

These developments are in line with changes in public and political discourse about crime, and take up the process of emotionalization that is characteristic of the public sphere of late modernity. The return of shame, restorative justice and the emotionalization of public discourse about crime and law, are responding to changes in wider emotional culture, and changing the moral imagination of these societies. The media engage their public in 'distant suffering' (Boltanski, 1999)—compassion and sympathy with victims, expressions of moral disgust towards offences and the perpetrators. An intensely emotional discourse about crime thus comes to be fuelled by the most recent and most heinous offence. Crime policies are explicitly based on the expression of collective emotions of fear and anger about crime. Politicians compete with each other in addressing the 'emotional' needs of the public, and in turn mirror these emotions back to the audience and the electorate. National and even global audiences become highly emotionalized 'moral spectators' in the spectacles of distant suffering of victims and perpetrators.

In a public sphere constituted by distant suffering, and the emotions it arouses and the moral commitment it induces, the task of criminal justice is extremely simplified: justice for victims means making offenders suffer the harshest punishment available. But as Boltanski shows, social distance and what Hirschman calls 'benevolent disinterest' are nonetheless required from truly moral spectators. They have to show a certain amount of impartiality and even, paradoxically, indifference if their emotions and moral commitment are to become authentic (Boltanski, 1999; Karstedt, 2000). The emotionalized discourse about crime and criminal justice in the 
public sphere is defined by the absence of such indifference and impartiality. Even if we do not agree with Charles Taylor (1992) that 'victimization' is the defining feature of public discourse in late modernity, a certain imbalance of public interest, moral commitment and compassion towards the victim is obvious. ${ }^{4}$ In Britain, public demands for representation of the emotions of victims in the criminal justice system have been widely supported. Their sorrow, rage and anger, and feelings of vengeance need to be voiced, and 'healed' by the sanction imposed on the offender. This imbalance in the collective emotional mood thus easily intrudes into the criminal justice system, where decisions disadvantage actual offenders.

The social context in which these developments take place is the increasingly emotionalized cultures of late modern societies (see Wouters, 1986; Vester, 1991; Barbalet, 1998; Neckel, 1999; Williams, 2001). ${ }^{5}$ Modern societies clearly stress individual autonomy and individual self-representation. This includes the open display of emotions and the claim that these have to be considered as singular and authentic expressions of the autonomy and identity of the individual. The significance of the expression of emotions corresponds to the importance of emotional experiences and fulfilment. Cross-cultural research shows that individuals are more risktaking and thrill-seeking-both intense emotional experiences-in modern societies than in more traditional ones (Triandis, 1994; Karstedt, 2001).

At the same time, individualization in the display of emotions and emotionality is juxtaposed by an extremely distant emotionality that characterizes the public sphere, the aforementioned feature of 'distant suffering'. The media bring home the 'spectacle' of suffering to very diffused spectators, and elicit strong emotional reactions like sorrow, rage, anger and compassion. ${ }^{6}$ Social movements and organizations try to convert these emotions into participation in their tasks and targets. Such distant moral sentiments are no longer embedded in direct interactions between individuals or in the social space of communities. As such they lack mutuality and duration, and become more fleeting and volatile. The objects of our compassion, anger and fear change quickly, the media operating with a keen sense of the half-life of emotional arousal in the public sphere.

Between the individualization of emotionality on the one hand, and distant emotionality on the other, the emotional space of groups seems to have been eroded. Joint experiences of emotions, emotions which are embedded in group rituals and the display of collective identity are not common in late modern societies. More often they take the form of deviant reactions-such as rioting or football hooliganism - when rage and anger is vented (see Dunning et al., 1986; Dunning, 1992; Frijda, 1996). The criminal law and criminal justice system respond to the bi-partite nature of emotionality in modern societies, on the one hand by opening up more space for the expression of individual emotions, on the other by increasingly responding to public and collective emotions. It comes as no surprise 
that shame has played a prominent role in this process, since this emotion establishes a link between the individual and the public sphere.

\section{Three core problems}

I want to explore the core problems and questions I outlined earlier using three exemplary 'stories'. The first two of these illuminate problems and questions related to the nature of the link between emotions, law and morality. Is the criminal justice system linked to and founded on basic emotional reactions towards crimes and offenders, and are such basic emotions constitutive of morality?

When I came to the UK in June 2000, I was soon confronted with a tabloid-led campaign of 'naming and shaming' paedophiles that followed the abduction and murder of 8-year-old Sarah Payne. The public reacted with an extreme display of emotions: strangers left flowers and teddy bears at the site where Sarah Payne's body had been found, the service became a media spectacle of outbursts of emotions, and vengeful groups gathered before the houses of those who had been named in a newspaper campaign as paedophiles. This differed considerably from what had taken place in Germany in a very similar case only a year before. Thousands of men had (more or less) voluntarily enlisted for a genetic test (by which route the offender was ultimately found), but the public display of emotional reactions was not comparable to what had taken place in Britain.

Emotional practices in public reactions towards crime are obviously and decisively shaped by specific emotional cultures and their institutional settings (such as modal national character, specific models, or characteristic features of the legal and political system), even if the cultures are otherwise very similar-as is the case with Britain and Germany-in their general emotional reactions (Mesquita et al., 1997; Mikula et al., 1998). This suggests that criminal justice is not based on specific basic emotions that are 'primordial' to its existence, but, rather, that the specific institutional and cultural pattern in which these emotions are embedded constitute and define the emotional reaction. Emotions seem to be only loosely coupled to the institutional framework which gives space to a diversity of emotions and emotional practices. The spontaneity of the public's emotional reaction in Britain confirms more a well-established cultural pattern than a collective 'natural response'.

My second exemplary story explores further the problem of basic emotions and their constitutive role in criminal justice. It was written by Plato in his Socratic dialogue 'Protagoras' (1987) nearly 2400 years ago. At the dawn of humankind, human beings were incapable of living together, their cities torn with violence and strife. Thus, Zeus feared that humankind was in danger of utter destruction. He sent his messenger who was, 
remarkably, the god both of merchants and thieves, down to earth with two gifts that should enable humankind successfully to establish communities and live together safely and amicably. These two gifts were shame and law, and Zeus gave orders to his messenger to distribute them equally among human beings. Thus, they were equally endowed with a 'moral sense' which was based on a strong emotion and gave them the capacity of autonomous moral judgements and, simultaneously, with a framework of common norms and principles.

It is clear that Plato posits a basic emotion-shame-as the foundation of morality and law, exactly the one that has figured prominently in the late modern return of emotions. Nonetheless, the link is not clear, and there are several types. Braithwaite adopts a position which can be described as 'functionalist', as for him shame as a moral sentiment has two functions in producing compliance: it inhibits people from transgressing the moral norms and laws, and it establishes the self as a moral self in one's own and others' eyes. According to the 'constitutive' position (Taylor, 1987) moral sentiments provide the motivation to comply with moral norms. Morality is based on the capacity of individuals to feel shame after having transgressed the norms, and accordingly the moral sentiment constitutes moral action. The 'indicative' link between emotions and morality establishes a relationship in which emotions are only the consequence or expression of moral engagement in one's own actions or those of others, and of moral principles which have been accepted. Moral sentiments are neither constitutive nor a motivation for moral action, but are attached to a moral principle and judgement (see Nunner-Winkler, 1998). This is essentially the position of Durkheim, that strong moral sentiments indicate strong moral norms, and reinforce these norms following their violation.

My final exemplary story explores a problem, one that becomes important when emotions return to criminal justice in an emotional culture, concerning the authenticity of emotions: their invisibility. ${ }^{7}$ In 1517, Martin Luther started Reformation in Germany by hammering his 95 propositions to the door of the church in Wittenberg. In about one-third of them, Luther argued that no institution could and should interfere with individual repentance, and feelings of shame and guilt, let alone use or exploit them for institutional purposes. Interestingly, in some of his main arguments he contended that only God-not even always the offender-could know if these feelings were authentic and truthful (Luther, undated).

What is important here is not that this was one of the many steps on the way towards individualism and modernity, but that Luther was aware of the invisibility of emotions and the problems this fact causes for any social institution that deals with them. How can we know that offenders really feel shame and remorse in restorative justice conferences? How 'true' are expressions of anger voiced by victims? Would we rate a restorative justice conference less successful if everyone present only pretended his/her feelings, or would we rely on their actions, or the final outcome? How fearful 
or angry are victims really, or do emotional public responses to, and demands for action against, crime (as witnessed in the campaign for 'Sarah's Law') merely indicate a public caught up in media and political scripts? 8

Obviously, the quest for authentic emotions in late modern societies and the fact that they are 'invisible' contradict each other, and even in societies where the authentic display of emotions is demanded and rewarded, people will hide many if not most of them. Significantly, shame cultures have ritualized and formalized the expression of shame, authenticity is not requested and the strength of emotions is not relevant. It is hard to discern if that has an impact on the intensity of the emotion. In the absence of such formalized emotional practices, the return of shame resulted in sentences and practices which tried to elicit an intense and authentic feeling of shame, and there were few restrictions on how that was achieved.

Answers to these questions and solutions to these problems will define the role and the space of emotions in criminal justice. Contemporary psychological theory has in particular addressed the problems of basic and universal emotions, how emotions are linked to social settings and the way cultural practices influence, regulate and define emotions.

\section{Perspectives from contemporary emotion theory}

Though an extremely diverse field, contemporary emotion theory does not conceptualize emotions as 'unitary, elementary entities' but instead as 'multi-componential phenomena'. ${ }^{9}$ Rather than assuming homogenous emotional states and a definite number of basic and universal emotions, emotion processes consisting of 'concurrent changes in several different components' are of central importance, thus making emotions dynamic.

Such a perspective is based on the notion that human beings have a universal emotional potential, but that this is realized in actual emotional practices, and in concrete social and cultural settings. Across cultures, emotions like anger and fear, or disgust and shame therefore simultaneously can be similar in some respects, and different in others. Expressions of emotions will vary from culture to culture even if they have a universal base. Thus, universal recognition of a particular facial expression as depicting anger, or blushing as a sign of shame, does not rule out the possibility that the counterparts of both emotions in other cultures may be different in those events that arouse them, and with regard to the actual emotional practices in which they are embedded. This applies equally to different contexts within a culture. The components of an emotion do not automatically follow from each other or from context-specific characteristics. A procedure explicitly designed to arouse shame may equally arouse feelings of humiliation and anger. Universality of emotions therefore can be 


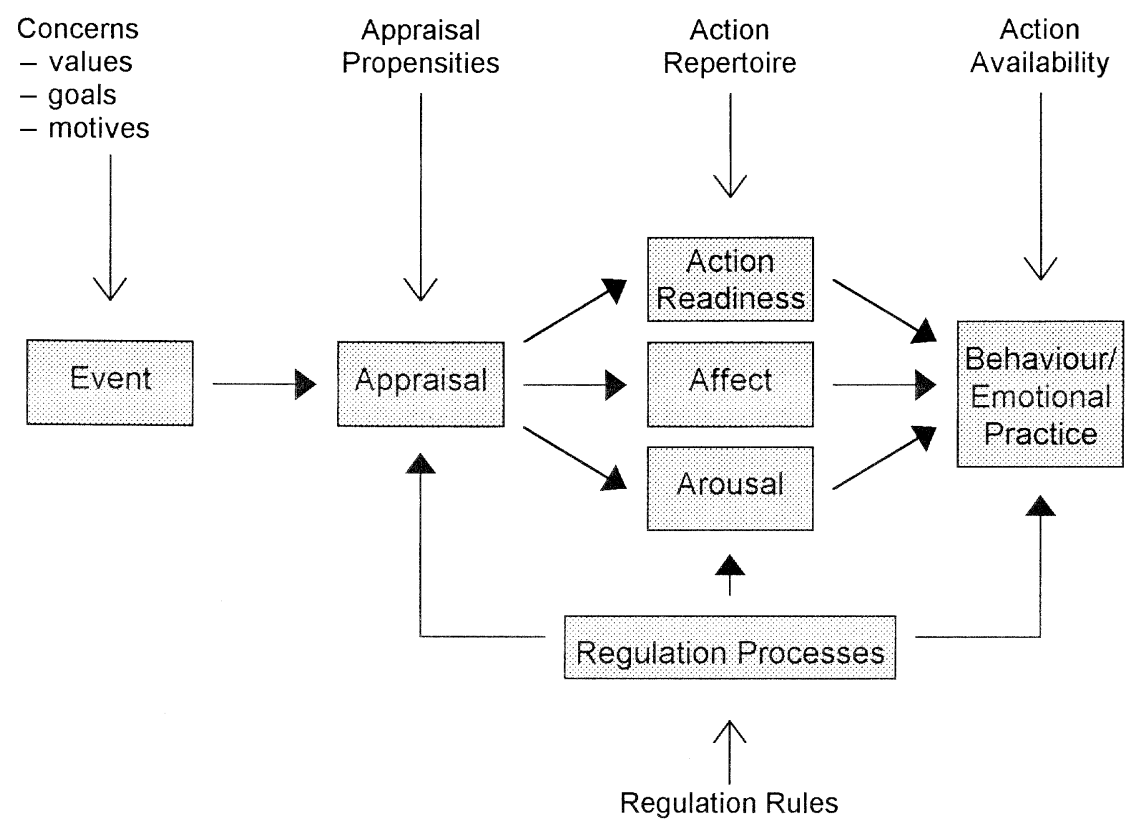

Figure 1 Component-process-model of emotions

Source: Adapted from Frijda (1996)

'established only for components of emotions rather than for emotions as a whole' (Mesquita et al., 1997: 259-60).

The emotion process (see Figure 1) includes the following components: an antecedent event, an emotional experience and an appraisal of the event, physiological change and change in action readiness, a specific behaviour or emotional practice, a change in cognitive functioning and beliefs and a regulatory process which determines its course. The intensity and 'power' of emotions (Frijda, 1996), drastic action impulses, long duration of feelings as in revenge (Frijda, 1994) or profound changes in beliefs, are caused by the interaction of these components and the strength of emotions built up during the process.

Emotions result from individual concerns that are essential in the definition and appraisal of a situation. In particular, individual goals, motives and values that relate individuals with social and common concerns emerge when an event is appraised as harming or threatening. Concerns like prestige and self-esteem, or the sense of belonging are linked to emotions of pride and shame. Concern for identity and autonomy arouses intense feelings of anger if not treated with respect and recognition, and being shamed is a most powerful source of rage and feelings of revenge. Research on ghetto youths has established the close link between violent behaviour and the 'search for respect' (Bourgois, 1995).

Most important here is the fact that individual concerns are derived from social values and common or even universal concerns, and thus link 
individual and collective emotions. Concerns arise from social and moral values of justice and fairness, which are universal to all cultures (see Schwartz, 1992, 1994; Schwartz and Sagiv, 1995). Concerns about basic moral principles are affected when these are injured. The collective nature of such concerns implies that not only individual experiences but equally experiences of others are events that are linked to emotions of anger as well as sympathy and compassion.

Regulation rules are a component of the emotion process that are particularly important for the development of shared emotional practices. They control and inhibit the display of emotions, they define the proper social space for emotions, and they restrict emotional action. The role of regulation rules becomes obvious when control is lifted within the social environment: when collective expressions of anger and disgust are encouraged, articulation of hatred is rewarded, or revenge is subtly praised (Frijda, 1996: 20). Regulation rules define the importance of emotions of victims, and the amount of display in social space, and they equally restrict the emotional space of offenders. Legal procedures provide an elaborately regulated space for emotions.

What then are the implications of contemporary emotion theory for the core problems of primordial emotions, basic emotions and the link between emotions, morality and the law?

One of the most important conclusions from contemporary emotion theory is that penal law and legal procedures are not built on 'basic emotions', but are part of the emotion process. They establish an institutional context and regulatory processes for a diversity of emotional components. In particular, legal procedures have the task of establishing those rules of justice and fairness that prevent additional arousal of emotions of anger and feelings of revenge, and that enhance the acceptance of the legal and moral judgment by the offender and the victim. Evidence from research on procedural justice shows that violations of these basic rules arouse those feelings, and as a consequence, decrease the readiness of offenders to accept the judgment and the moral rationale behind it (Tyler, 1990). Resulting feelings of anger and revenge might change beliefs about the fairness and legitimacy of these institutions profoundly. The most important components of fairness rules are that offenders can tell 'their stories', that they are not humiliated before their own peer group and that their self-esteem is not stripped from them. Cross-cultural research has provided evidence of the universality of these values as well as of their importance in legal procedures (Schwartz, 1992). It is highly probable that the 'return of shame' to the courtrooms will violate these rules, and arouse much more anger and revenge in those who are treated in this way.

Contemporary emotion theory suggests that legal procedures and punishment fulfil different tasks and are linked to different emotion processes. The secular changes of penal sanctions during the last centuries provide ample evidence from history that penal punishments are not linked to 
universal and basic moral sentiments, but are embedded into the moral imagination of societies and the context of imagined communities (Anderson, 1983). The spectacle of public executions obviously aroused thrill and excitement among the crowds, and it took some efforts during the 19th century to make it a more sombre event until they were finally banned from public view (Pratt, 2000).

The theory would imply further that a diversity of emotions is involved in the process of punishment, and that different emotions restrict and balance each other. It stresses the situational pattern in which emotions are aroused, and the importance of appraisal processes. Punishment is rarely imposed by those who were victims of the offence, and the emotions involved on the side of those who punish have barely got consideration (but see Elster, 1989). Parents or teachers mostly punish children for what they did to others. The type and severity of the punishment imposed by them therefore results from the social bonds that are established and the emotions of love and sympathy attached to them; these function as inhibitors to extremely severe reactions. Research on the expectations and experiences of sanctions by juvenile offenders shows that parents normally do not react in a way that would endanger those bonds, but try instead to secure and confirm these bonds in their reactions to an offence committed by their children (Karstedt, 1989, 1993). Courts and juries that are embedded in communities have hesitated to give death sentences, as in the case of a young woman who had murdered her two children. As long as victims were directly involved in the punishment of offenders, practices of restorative justice prevailed (Braithwaite, 2001). In the present context of the spectacle of 'distant suffering' where such bonds do not exist, the lack of inhibiting emotions of sympathy and empathy seems to give way to excessive demands for punishment by 'moral spectators'.

Contemporary emotion theory clearly refutes the notion that moral principles and the edifice of law are erected on basic and universal sentiments, and that the latter constitute these principles. Instead, moral principles and axioms of justice and fairness define the concerns, and thus the events that arouse 'moral sentiments'. Consequently, emotions like anger and disgust and shame are 'indicators' of our moral beliefs and convictions-they do not constitute them. 'Once established, justice is naturally attached with a strong sentiment of morals' (Hume, A Treatise of Human Nature, cited in Solomon, 1990: 198), but justice needs to be established first. Evidence from longitudinal research on the moral development of children shows that very young children understand moral principles (right versus wrong) but do not attach moral sentiments to them. These are developed at a later stage, the process of attachment being mostly finalized at the age of 10 (Nunner-Winkler, 1998). In particular, historical change and cultural diversity of emotions of moral disgust show that these emotions are linked to antecedent moral judgments and do not constitute them, as I will discuss in the following section. 


\section{Disgust, anger, shame: some cautious notes on the use of emotions in criminal justice}

The recent discourse about law and emotions has been dominated by three emotions-disgust, anger and shame. Though this discourse lingers between constructionist perspectives and assumptions about 'primordial' emotions, between a constitutive, functionalist and indicative role of emotions for law and morality, there is nonetheless a strong consensus that emotions could and should be used in the legal sphere and in lawmaking more than in the past.

As noted above, legal theorists have identified disgust as a legitimate and valuable barometer of societal morality (Bandes, 1999a: 4; Kahan, 1999; Posner, 1999, 2000). Disgust should and could have a legitimate place in the legal arena. It has been argued that law should shape the cognitive contents of the emotion by leading us to feel disgust for heinous but not sufficiently punished acts like racial violence or hate crimes (Kahan, 1999; see Poletta, 2001 for a critique). In particular, the latter-more constructionist-perspective is in line with conclusions from emotion theory. Nonetheless, it has to be stressed here that universal components in the emotion process are embedded into concrete cultural settings which define the content of moral rules, and thus the situations when disgust is elicited. Cross-cultural studies in more than 35 countries show that feelings of disgust are mostly and universally related to moral evaluations and events of violation of moral norms, in contrast to anger, which is related to experiences of injustice (Scherer, 1991, 1997).

However, the fuelling of emotions of disgust has led societies to treat marginalized groups as if they were less than human, and in particular has instigated racial violence amounting to genocide (Nussbaum, 1999). In his book Ordinary Men, Browning (1992) shows how the members of a police battalion in occupied Poland voiced their disgust about the Jewish population, and how they used this emotion in their moral legitimation of the mass murder in which they participated. ${ }^{10}$ These emotions had been consistently fuelled among the population during the Nazi Regime (and before), and this process was related to laws that step-by-step deprived the Jewish population in Germany of their civil and finally human status. Most infamous in this process were the Nuremberg Laws issued in 1936, which prohibited marriages between Jews and other Germans, and barred Jews from employing German girls in their households and businesses with accompanying propaganda that Jews were paedophiles. Existing moral norms and the emotions attached to them were thus used to direct emotional reactions of disgust towards the marginalized group. Disgust is 'brazenly and uncompromising judgmental' (Nussbaum, 1999: 21) and therefore comes with a powerful potential for disruptive and violent consequences. As much as it might be 'necessary ... for perceiving and motivating opposition to cruelty' (Nussbaum, 1999: 21), disgust is also heavily implicated in the commission of cruelty. Using it in the legal realm 
as a 'barometer of social morality' deprives the law of much of its own potential of establishing justice and fairness.

Anger is the emotion most clearly linked to concerns and values about justice and fair treatment (Frijda, 1996; Mesquita et al., 1997; Scherer, 1997). Notwithstanding cultural differences with regard to the intensity and the display of anger, the emotional link seems to be universal. We get angry when we and others are not treated fairly, or are humiliated, or when our social position and self-esteem are hurt. Legal procedures have a central role in society as they provide justice, both channelling such feelings and simultaneously arousing them. Anger of victims of crime might be linked to such a sense of 'unfair' treatment by fellow citizens. But it is much less clear how 'anger about crime' is aroused in those who have not been a victim and who have no personal experience of crime (Farrall, 2001). What kind of concerns and emotional experiences are involved, and what are the underlying emotion components and processes, when a majority of the population declares that they are 'angry about crime'? Before designing 'affective crime prevention policies' (Freiberg, 2001) that take into account such emotional processes, we need to establish which kind of emotion and emotion process are involved, if at all.

Shame, remorse and guilt are emotions most closely linked to the criminal justice system and the community it represents. Among them shame is defined as the emotion that is embedded in the bonds to groups and communities, and therefore a visible physiological reaction-blushing-is attached to it. Shame is a tremendously complex emotion, dependent on specific contexts, related to a range of other emotions, and actions (Lewis, 2000). Violations of self-esteem, humiliation and stigmatization cause shame as well as anger, varying with the context and the concerns. Obviously, legal procedures have the potential to evoke shame in offenders, but like other modern institutions they do not require particular emotional reactions. ${ }^{11}$ The return of shame might have counterproductive consequences when shame interferes with procedural justice and fairness, and causes anger and defiance.

Legal institutions are not based on a small number of basic emotions, but on different and contradictory ones. Processes of punishment are linked to feelings of disgust as well as being embedded in emotions of sympathy. Any efforts to bring one of these to the forefront, and make it the foundation of criminal justice procedures, will necessarily ignore the range of moral sentiments which are involved in the individual as well as in the collective. The fact that emotional reactions are attached to moral norms does not necessarily imply the strategic use of emotions in, for example, defining laws against hate crimes or violations of human rights. The complex and complicated role and space of emotions within the legal system does not allow for easy solutions. 


\section{Notes}

1. The place of emotions is not assigned exclusively to the criminal court. Tort laws and family courts similarly deal with intense emotions.

2. Research consistently shows that victims mostly want to have their damage restored, and that they are rarely vengeful in their demands for punishment for the offender (Sessar, 1992). Victims seem to be, in particular, sensitive to the impact of legal action within their social networks.

3. See, for revisions of the theory and practice, Ahmed et al. (2001).

4. At the turn of the 18th to the 19th century, public emotions and compassion started to be directed towards the offender, in particular those who were imprisoned. The attack on the Bastille during the French Revolution was driven by public outrage about innocent prisoners (though they were actually quite comfortably accommodated); operas like Beethoven's Fidelio show how public emotions were expressed in the arts. The 'longue durée' of compassion with the offender as a victim of society, which lasted through the 19th and 20th century, seems today to have come to a halt.

5. In terms of Elias' theory of the civilization process, these developments are often analysed as 'de-civilization' (Fletcher, 1995, 1997; Pratt, 2000). Nonetheless, this perspective only grasps the regulation or de-regulation of the expression of emotions, and implies a strong bias towards processes of social control.

6. When I asked a movie director why people cry in the cinema, but not in the theatre, his answer was clear and to the point: 'Close-ups'.

7. See Katz (1999: 316) for a more detailed discussion.

8. See Farrall (2001) for an exploration of 'anger' about crime. His results show that 'anger about crime' seems to be more an emotional reaction that people feel they ought to have than an actual emotional experience. Jones and Newburn (2002) show that notwithstanding public outrage and support for 'Sarah's Law', its final failure in Britain shows it not to be a solely emotionalized public issue.

9. Ekman and Davidson (1994), and Lewis and Haviland-Jones (2000) provide excellent overviews.

10. Since Browning analysed the files of the investigation and ensuing interrogation that took place some 10 years later, these are memories of emotions, which nonetheless seemed to be still extremely vivid at that time. These emotions of disgust were expressed at a time when the moral code had been definitely changed, at least officially and in public.

11. We are not required to feel emotions about our work, or our superiors, or what we produce. Nonetheless, in a recent case in Britain the lack of display of shame and remorse by the offender was the reason explicitly given for a severe sanction. 


\section{References}

Ahmed, Eliza, H. Nathan, J. Braithwaite and V. Braithwaite (2001) Shame Management through Reintegration. Cambridge: Cambridge University Press.

Anderson, Benedict (1983) Imagined Communities. Reflections on the Origins and Spread of Nationalism. London: Verso.

Anderson, Digby (ed.) (1995) This Will Hurt. The Restoration of Virtue and Civic Order. London: The Social Affairs Unit.

Bandes, Susan A. (1999a) 'Introduction', in S. Bandes (ed.) The Passions of Law. New York: New York University Press.

Bandes, Susan (ed.) (1999b) The Passions of Law. New York: New York University Press.

Barbalet, Jack M. (1998) Emotion, Social Theory and Social Structure. A Macrosociological Approach. Cambridge: Cambridge University Press.

Boltanski, Luc (1999) Distant Suffering. Morality, Media and Politics. Cambridge: Cambridge University Press.

Bourgois, Philippe (1995) In Search of Respect. Selling Crack in El Barrio. Cambridge: Cambridge University Press.

Braithwaite, John (1989) Crime, Shame and Reintegration. Cambridge: Cambridge University Press.

Braithwaite, John (2001) 'Crime in a Convict Republic', The Modern Law Review 64(1): 11-50.

Browning, Christopher (1992) Ordinary Men: Reserve Police Battalion 101 and the Final Solution in Poland. New York: HarperCollins.

Douglas, Mary (1993) 'Emotion and Culture in Theories of Justice', Economy and Society 22(4): 501-15.

Dunning, E. (1992) '“Culture”, "Civilization" and the Sociology of Sport', Innovation: The European Journal of Social Sciences 5(4): 7-19.

Dunning, E., P. Murphy and J. Williams (1986) 'Spectator Violence at Football Matches: Towards a Sociological Explanation', British Journal of Sociology 37(2): 221-44.

Ekman, Paul and Richard R. Davidson (eds) (1994) The Nature of Emotion. Fundamental Questions. Oxford: Oxford University Press.

Elster, Jon (1989) The Cement of Society. Cambridge: Cambridge University Press.

Elster, Jon (1999) Alchemies of the Mind. Rationality and Emotions. Cambridge: Cambridge University Press.

Farrall, Stephen (2001) 'Anger, Fear and Victimisation: Emotional Responses without Emotions', paper presented at joint meetings of Law and Society Association and Research Committee on the Sociology of Law (ISA), Central European University, Budapest, July.

Fletcher, Jonathan (1995) 'Towards a Theory of Decivilizing Processes', Amsterdams Sociologisch Tijdskrift 22(3): 283-96.

Fletcher, Jonathan (1997) Violence and Civilization. An Introduction to the Work of Norbert Elias. Cambridge: Polity. 
Freiberg, Arie (2001) 'Affective Versus Effective Justice. Instrumentalism and Emotionalism in Criminal Justice', Punishment and Society 3(2): 265-78.

Frijda, Nico H. (1994) 'The Lex Talionis: On Vengeance', in S. van Goozen, N. van de Poll and J. Sergeant (eds) Emotions: Essays in Emotion Theory, pp. 264-89. Hillsdale: Lawrence Erlbaum.

Frijda, Nico H. (1996) 'Passions: Emotion and Socially Consequential Behavior', in R. Kavanaugh, B. Zimmerberg and S. Fein (eds) Emotion. Interdisciplinary Perspectives, pp. 1-27. Mahwah: Lawrence Erlbaum.

Jones, Trevor and Tim Newburn (2002) 'Policy Convergence and Crime Control in the USA and UK: "Streams" of Influence and "Levels" of Impact', Criminal Justice 2(2).

Kahan, Dan M. (1999) 'The Progressive Appropriation of Disgust', in S. Bandes (ed.) The Passions of Law, pp. 63-79. New York: New York University Press.

Karstedt, Susanne (1989) 'Sanktionserfahrungen und Sanktionserwartungen von Jugendlichen. Eine Empirische Studie zur Integration von Individualund Generalpraevention', in Bundesministerium der Justiz (ed.) Jugendrechtsreform durch die Praxis, pp. 168-96. Bonn: Bundesministerium der Justiz.

Karstedt, Susanne (1993) Webs of Significance, Nets of Control. Experiences and Expectations of Sanctions by Juveniles. Bielefeld: University of Bielefeld.

Karstedt, Susanne (1996) 'Recht und Scham', Neue Kriminalpolitik 8(4): 22-5.

Karstedt, Susanne (2000) 'Review: Distant Suffering. Morality, Media and Politics', The Sociological Review 48(4): 670-2.

Karstedt, Susanne (2001) 'Die moralische Staerke schwacher Bindungen: Individualismus und Gewalt im Kulturvergleich', Monatsschrift fuer Kriminologie und Strafrechtsreform 84(3): 226-43.

Katz, Jack (1999) How Emotions Work. Chicago, IL: University of Chicago Press.

Laster, Kathy and Pat O’Malley (1996) 'Sensitive New-Age Laws: The Reassertion of Emotionality in Law', International Journal of the Sociology of Law 24(1): 21-40.

Lewis, Michael (2000) 'Self-Conscious Emotions: Embarrassement, Pride, Shame and Guilt', in M. Lewis and Jeanette M. Haviland-Jones (eds) Handbook of Emotions, 2nd edn, pp. 623-36. New York: Guilford Press.

Lewis, Michael and Jeanette M. Haviland-Jones (eds) (2000) Handbook of Emotions, 2nd edn. New York: Guilford Press.

Luther, Martin (undated) Die 95 Thesen Martin Luthers. Wittenberg: Horst Bargmann Verlag fuer Kunst und Touristik.

Massaro, Toni M. (1991) 'Shame, Culture, and American Criminal Law', Michigan Law Review 89(6): 1880-944.

Massaro, Toni M. (1997) 'The Meanings of Shame', Psychology, Public Policy, and Law 3(4): 645-704. 
Mesquita, Batja, Nico H. Frijda and Klaus R. Scherer (1997) 'Culture and Emotion', in J.W. Berry, P.R. Dasen and T.S. Saraswathi (eds) Basic Processes and Human Development. Handbook of Cross-Cultural Psychology, vol. 2, pp. 255-97. Boston, MA: Allyn \& Bacon.

Mikula, Gerold, Klaus R. Scherer and Ursula Athenstaedt (1998) 'The Role of Injustice in the Elicitation of Differential Emotional Reactions', Personality and Social Psychology Bulletin 24(7): 769-83.

Neckel, Sighard (1999) 'Blanker Neid, Blinde Wut. Sozialstruktur und Kollektive Gefuehle', Leviathan 27(2): 146-65.

Newsweek (1995) 'The Return of Shame', 6 February.

Nunner-Winkler, Gertrud (1998) 'Empathie, Scham und Schuld: Zur Moralischen Bedeutung von Emotionen', in M. Grundmann (ed.) Konstruktivistische Sozialisationsforschung: Ansaetze und Methodische Ueberlegungen zu einer Konstruktivistischen Theorie der Sozialisation, pp. 118-43. Frankfurt: Suhrkamp.

Nussbaum, Martha C. (1999) “"Secret Sewers of Vice”: Disgust, Bodies and the Law', in S. Bandes (ed.) The Passions of Law, pp. 19-62. New York: New York University Press.

Plato (1987) Protagoras. Greek/German, translated and commented by H.-W. Krautz. Stuttgart: Philipp Reclam jun.

Poletta, Francesca (2001) 'The Laws of Passion. Reviewing Bandes's The Passions of Law', Law and Society Review 35(2): 467-94.

Posner, Richard A. (1999) 'Emotion Versus Emotionalism in Law', in S. Bandes (ed.) The Passions of Law, pp. 309-29. New York: New York University Press.

Posner, Richard A. (2000) Law and the Emotions. John M. Olin Law and Economics Working Paper No. 103. Chicago, IL: The Law School, University of Chicago.

Pratt, John (2000) 'Emotive and Ostentatious Punishment: Its Decline and Resurgence in Modern Society', Punishment and Society 2(4): 417-41.

Scherer, Klaus (1991) 'Die Emotionalen Grundlagen des Gerechtigkeitsgefuehls', in D. Frey and G. Koehnken (eds) Bericht ueber den 37. Kongress der Deutschen Gesellschaft fuer Psychologie in Kiel 1990, pp. 411-20. Goettingen: Hogrefe.

Scherer, Klaus (1997) 'The Role of Culture in Emotion-Antecedent Appraisal', Journal of Personality and Social Psychology 73(4): 902-22.

Schwartz, Shalom H. (1992) 'Universals in the Content and Structure of Values: Theoretical Advances and Empirical Tests in 20 Countries', in M.P. Zanna (ed.) Advances in Experimental Psychology, vol. 25, pp. 1-65. Orlando, FL: Academic Press.

Schwartz, Shalom H. (1994) 'Are There Universals in the Structure and Contents of Human Values?', Journal of Social Issues 50(4): 19-45.

Schwartz, Shalom H. and Lilach Sagiv (1995) 'Identifying Culture-Specifics in the Content and Structure of Values', Journal of Cross-Cultural Psychology 26(1): 92-116. 
Sessar, Klaus (1992) Widergutmachen oder Strafen. Einstellungen in der Bevoelkerung und der Justiz. Pfaffenweiler: Centaurus.

Skillen, A.J. (1980) 'How to Say Things with Walls', Philosophy 55(5): 509-23.

Solomon, Robert C. (1990) A Passion for Justice. Emotions and the Origins of the Social Contract. Reading, MA: Addison-Wesley.

Solomon, Robert C. (1994) 'Sympathy and Vengeance: The Role of the Emotions in Justice', in S. van Goozen, N. van de Poll and J. Sergeant (eds) Emotions: Essays in Emotion Theory, pp. 291-311. Hillsdale: Lawrence Erlbaum.

Taylor, Charles (1992) Multiculturalism and 'the Politics of Recognition'. An Essay. Princeton, NJ: Princeton University Press.

Taylor, Gabriele (1987) Pride, Shame, and Guilt. Oxford: Clarendon.

Triandis, Harry C. (1994) 'Major Cultural Syndromes and Emotions', in S. Kitayama and H.R. Markus (eds) Emotion and Culture. Empirical Studies of Mutual Influence, pp. 285-306. Washington, DC: American Psychological Association.

Tyler, Tom R. (1990) Why People Obey the Law. New Haven, CT: Yale University Press.

Vester, Heinz-Guenter (1991) Emotion, Gesellschaft und Kultur. Grundzuege einer Soziologischen Theorie der Emotionen. Opladen: Westdeutscher Verlag.

Williams, Simon J. (2001) Emotion and Social Theory. Corporeal Reflections on the (Ir)Rational. London: Sage.

Wouters, Cas (1986) 'Formalization and Informalization: Changing Tension Balances in Civilizing Processes', Theory, Culture and Society 3(2): 1-18.

SUSANNE KARSTEDT is Professor of Criminology in the Department of Criminology, Keele University, UK. She has researched and published on cross-cultural criminology, in particular violence and corruption, elite criminality, social capital and violence and transitional justice. She is presently directing a comparative research project on the moral economy of modern market societies, funded by the Volkswagen Foundation. 